\title{
Fuscibacter Oryzae Gen. nov., sp. nov., A Phosphate- Solubilizing Bacterium Isolated from the Rhizosphere of Rice Plant
}

\section{Geeta Chhetri}

Dongguk University

\section{Minchung Kang}

Dongguk University

Jiyoun Kim

Dongguk University

Inhyup Kim

Dongguk University

\section{Yoonseop So}

Dongguk University

\section{Taegun Seo ( $\nabla$ tseo@dongguk.edu )}

Dongguk Univesity https://orcid.org/0000-0001-9701-2806

\section{Research Article}

Keywords: Fuscibacter oryzae, non-phototrophic, binary fission, phosphate-solubilization, brown-pigment

Posted Date: June 29th, 2021

DOl: https://doi.org/10.21203/rs.3.rs-382391/v1

License: (1) This work is licensed under a Creative Commons Attribution 4.0 International License. Read Full License

Version of Record: A version of this preprint was published at Antonie van Leeuwenhoek on July 17th, 2021. See the published version at https://doi.org/10.1007/s10482-021-01619-2. 


\section{Abstract}

An ovoid to rod shaped, white tobrown pigmented, facultative anaerobic, mesophilic, non-phototrophic, Gram-staining-negative, non-motile, multiply by binary fission designated strain $\mathrm{KVB}^{2}{ }^{\top}$, which was isolated from root of rice plant, near Ilsan, South Korea, was investigated for its taxonomic position by polyphasic approach. Optimal growth was found to occur at $30^{\circ} \mathrm{C}$, at pH 6.5 and in the absence of $\mathrm{NaCl}$ on R2A. Phylogenetic analysis based on the $16 \mathrm{~S}$ rRNA gene sequence of strain KVB23 ${ }^{\top}$ revealed that it formed a distinct lineage, as a separate deep branch within the family Rhodobacteriaceae, with $<96.5 \%$ sequence similarity to representatives of the genera Rhodobacter, Xinfangfangia, Tabrizicola, Falsirhodobacter, Haematobacter, Paenirhodobacter, Pseudorhodobacter and Pararhodobacter. Based in 16S rRNA sequences strain KVB23 ${ }^{\top}$ was most closely related to Tabrizicola fusiformis KCTC $62105^{\top}$ (96.5\%) and Rhodobacter thermarumKCTC $52712^{\top}(96.2 \%)$. The draft genome of strain $\mathrm{KVB}^{\top} 3^{\top}$ was 3.80 bp long with a DNA G + C content of $63.1 \%$. Genome of strain $\mathrm{KVB}^{2} 3^{\top}$ harboured gene clusters for tryptophan and cobalaminbiosynthesis. The strain contained Q-10 as the sole respiratory quinone. The predominant fatty acids were found to consist of $\mathrm{C}_{16: 0}, \mathrm{C}_{18: 0}$ and summed feature 8 (comprising $\mathrm{C}_{18: 1}$ $\omega 7 \mathrm{c}$ and / or $\left.\mathrm{C}_{18: 1} \omega 6\right)$. The polar lipids were identified as diphosphatidylglycerol, phosphatidylethanolamine,seven unidentified phosphoglycolipids, two unidentified aminophosphoglycolipid, one unidentified glycolipid and four unidentified lipids.Phosphate-solubilizing bacteria have the ability to dissolve insoluble phosphates and enhance the soil fertility. Strain $\mathrm{KVB} 23^{\top} \mathrm{can}$ solubilize calcium phosphate tribasic. Phosphate solubilizing and tryptophan biosynthesis property of strain $\mathrm{KVB}^{2} 3^{\top}$ could be a possible factor for the increase in growth of rice plant. Differential phenotypic, chemotaxonomic and genotypic properties, together with the phylogenetic distinctiveness, demonstrated that strain $\mathrm{KVB}_{2} 3^{\top}$ was found to represent a novel genus in the Rhodobacteriaceaefamily, for which the name Fuscibacteroryzae gen. nov., sp. nov. is proposed, with the type strain $\mathrm{KVB}^{2} 3^{\top}$ (=KACC $21711^{\top}$ $=$ NBRC $\left.114716^{\top}\right)$.

\section{Repositories}

The draft genome and 16S rRNA gene sequences of strain KVB23T have been deposited at GenBank/EMBL/DDBJ under accession numbers JAESVP000000000 and MN955430 respectively.

\section{Introduction}

The Rhodobacteriaceae familywas first established by Garrity et al. (2005) as a sole member of the order Rhodobacterales within the class Alphaproteobacteria andphylum Proteobacteria.Rhodobacteriaceaeis one of the most widely distributed bacterial lineages in marine habitats such as seawater, sediments, marine snails, marine sponges and marine phytoplankton etc. Theyare mainly aerobic photoheterotrophs and chemoheterotrophs however, they can also exist as purple non-sulfur bacteria, which perform photosynthesis in anaerobic environments (Garrity et al. 2005). The members are Gram-stain-negative, oval-shaped and non-spore-forming bacteria. Most of the species are positive for oxidase activity. 
Pigmentation occurs not only in photosynthetic members but also in non-phototrophic members. Some membersproduce polyhydroxyalkanoates (PHBs). The $\mathrm{G}+\mathrm{C}$ content of genomic DNA ranges from 58.5 to $65.0 \mathrm{~mol} \%$ (Hetharua et al. 2018). Q-10 is the predominant isoprenoid quinone and the major fatty acid is unsaturated fatty acid C18:1 $\omega 7 c$. There are approximately 220 recognized genera in the family at the time of writing (https://lpsn.dsmz.de/family/rhodobacteraceae).In the course of screening the bacterial diversity in the roots of rice plants near Dongguk university, Ilsan, South Korea, strain KVB23T was isolated from a paddy field in the, Republic of Korea.Phosphate solubilizing bacteria play important role in biogeochemical phosphorus cycling in both terrestrial and aquatic environments (Das et al. 2007). In the present study, we introduce a novel non-phototrophic and phosphate-solubilizingbacterium isolated from the roots of rice plants that belongs to a new genus associated with the family Rhodobacteriaceae.

\section{Materials And Methods}

\section{Isolation of the novel strain and cultivation}

For assessing the diversity of culturable bacteria in the roots of rice plant, root samples were collected from a paddy field near Dongguk University, Ilsan, South Korea (GPS positioning of the sample collection site; $37^{\circ} 40^{\prime} 26.4^{\prime \prime} \mathrm{N} 126^{\circ} 48^{\prime} 20.88^{\prime \prime} \mathrm{E}$ ). The samples were placed in sterile polyethylene bags and brought back to the laboratory. For the isolation of strain $\mathrm{KVB}^{2} 3^{\top}$, the root samples were thoroughly washed with sterilized water, to remove the external soil that was clinging to the surface of roots. The roots were cut into small fragments and macerated using a sterile pestle and mortar in sterile distilled water. The macerated samples were serially diluted using $0.85 \% \mathrm{NaCl}$ as described previously (Chhetri et al. 2020a). Isolation was achieved using R2A agar (Difco) at $28^{\circ} \mathrm{C}$ for 1 week. A single colony chosen on the plates was purified by transferring it to new R2A plates. Pure culture of strain $\mathrm{KVB}^{2} 3^{\top}$ was obtained by their repeated transfer on R2A agar plates and the purified colonies were sent to Bionics (Daejeon, Republic of Korea) for $16 \mathrm{~S}$ rRNA gene analysis. From the purified bacterial colonies, a novel strain of the genus was identified to be a member of Fuscibacterand designated as $\mathrm{KVB}^{2} 3^{\top}$. The isolate was preserved in R2A broth (Difco) supplemented with $50 \%(\mathrm{v} / \mathrm{v})$ glycerol at $-80^{\circ} \mathrm{C}$. The reference strains Tabrizicola fusiformisKCTC62105 ${ }^{\top}$, Rhodobacter thermarumKCTC52712 ${ }^{\top}$ and Falsirhodobacter desertiKCTC32408 ${ }^{\top}$ were purchased from KCTC (Korean Collection for Type Cultures).

\section{Morphological characteristics}

Colony morphology was studied on R2A medium at $30^{\circ} \mathrm{C}$ for 5 days. The cell morphology and dimension were visualised by negative staining with $1 \%(\mathrm{w} / \mathrm{v})$ phosphotungstic acid and viewing under a transmission electron microscope (TEM) (LIBRA 120, Carl Zeiss, Germany) after 3 days of incubation in R2A agar at $30^{\circ} \mathrm{C}$.

\section{Physiological and biochemical characteristics}

To determine the optimal temperature range for growth, the growh of the strain was assessed at a temperature range of $4-40^{\circ} \mathrm{C}\left(0,2,4,10,15,20,25,28,30,35,37\right.$ and $\left.40^{\circ} \mathrm{C}\right)$ was measured by observing 
the formation of colonies on R2A to estimate the optimal temperature range for growth. The growth of the strains on different media was assessed at $30^{\circ} \mathrm{C}$ for 10 days using R2A agar (Difco), Trypticase soy agar, Marine agar, nutrient agar, Luria-Bertani agar and MacConkey. The requirement for $\mathrm{NaCl}$ was determined using R2A broth containing various concentrations of $\mathrm{NaCl}(0.2$ increments, w/v) was tested in $\mathrm{R} 2 \mathrm{~A}$ medium at $\mathrm{pH} 7.0$ by incubation for 10 days at $30^{\circ} \mathrm{C}$. Cell growth at various $\mathrm{pH}$ values in R2A broth ( $\mathrm{pH} 4.0-10.0$, in intervals of $1.0 \mathrm{pH}$ unit) was examined using the following buffer systems as described previously: citrate/ $\mathrm{NaH}_{2} \mathrm{PO}_{4}$ buffer (for $\mathrm{pH}$ 4.0-5.0), phosphate buffer (for pH 6.0-8.0) and Tris buffer (for pH 9.0-10.0) (Chhetri et al. 2018). Anaerobic growth was assessed by checking for colony formation on R2A agar at $30^{\circ} \mathrm{C}$ for two weeks in a GasPak jar (BBL, Cockeysville, MD, USA). Motility was assessed in R2A medium containing $0.4 \%$ agar. Gliding motility was tested using the hanging-drop method after growing the cells in R2A broth (Difco) for $48 \mathrm{~h}$ at $30^{\circ} \mathrm{C}$ (Bernardt et al. 2002). Gram reaction was determined using the non-staining KOH lysis method (Fautz and Reichenbach, 1980). Test for catalase and oxidase activities were performed using 3\% (v/v) hydrogen peroxide solution and oxidase reagent, respectively as described previously (Kim et al. 2020). The presence of flexirubin-type pigments was investigated by performing the bathochromic shift test with $20 \% \mathrm{KOH}(\mathrm{w} / \mathrm{v})$ (Kim et al. 2019). The hydrolysis of Tween 20, 40, 60 and 80 was assessed according to the method described by Simbert \& Krieg (1994). Moreover, the hydrolysis of chitin, carboxymethyl-cellulose, starch, and casein was also assessed according to a previously described method (Chhetri et al. 2019a). DNase activity was detected on DNase test agar by using toluidine blue. Additional enzyme activities, biochemical features and physiological characteristics were tested using the API 20NE and API ZYM kits (bioMérieux) according to the manufacturer's instructions. Since the strain $\mathrm{KVB}^{2} 3^{\top}$ was isolated from the roots of rice plantsits nitrification ability was assessed.Jensen's nitrogen free medium was used for this purpose, and bromothymol blue (BTB) was used as an indicator. Growth of strain $\mathrm{KVB}^{2} 3^{\top}$ in nitrogen free medium was observed for one week. Pikovakaya's (PVK) media was used to check the phosphate solubilizing activity of strain $\mathrm{KVB}^{2} 3^{\top}$.

\section{Phylogenetic and genotypic analysis}

Genomic DNA was extracted using the TaKaRa MiniBEST Bacteria Genomic DNA extraction Kit version 3.0 (TaKaRa) following the manufacturer's instructions. The 16S rRNA gene of the isolate was directly amplified by colony-PCR using the universal bacterial primers pairs 27F, 518F, 805R and 1492R; the PCR products were commercially sequenced (Solgent, Korea). The nearly complete sequence (1415bp) of the 16S rRNA gene was deposited to NCBI GenBank under accession number MN955430 after assembled with SeqMan software (DNASTAR). The pairwise 16S rRNA gene sequence similarities, were calculated and phylogenetic neighbours were identified based on sequences of bacterial type strains from the EzBiocloud server database (Kim et al. 2012). Multiple sequences were aligned using MEGA 7.0 software (Kumar et al. 2016) and analyzed using the CLUSTALX2.1 (Thompson et al. 1997). A phylogenetic tree was constructed according to the neighbour-joining ( $\mathrm{NJ}$ )(Felsenstein, 1985), maximum-parsimony (MP) and maximum-likelihood (ML) methods with the Kimura two-parameter model (Kimura,1980). Minimumevolution tree was also constructed using the MEGA 7.0 software in order to estimate the confidence of 
tree topologies (Rzhetsky and Nei 1992). MEGA 7.0 software was used to construct a phylogenetic tree by bootstrap analysis with 1000 replications (Felsenstein, 1985).

For genome sequencing, a standard DNA library was prepared using the TruSeq DNA PCR-Free kit library (Illumina). Subsequently, whole genome sequencing was performed by de novo sequencing analysis using an Illumina Hiseq 4000 sequencerwith a paired-end read length of $151 \mathrm{bp}$ and assembled with the SPAdes Analysis v.3.10.1 at Macrogen (Republic of Korea). Average nucleotide identity (ANI) and digital DNA-DNA hybridization values between the strain $\mathrm{KVB}^{2} 3^{\top}$ and closely related strain were calculated using ANI calculator (www.ezbiocloud.net/tools/ani), and the Genome-to-Genome Distance Calculator (GGDC 2.1; https://ggdc.dsmz.de/ggdc.php) (Meier-Kolthoff et al. 2013). To obtain more sufficient taxonomic evidence, UBCG phylogenomic tree based on the core genomes was constructed ( $\mathrm{Na}$ et al. 2018). Publicly available genomes of closely related taxa were used.The DNA G+C content of strain $\mathrm{KVB} 3^{\top}$ was calculated from the genome data.Genes involved in secondary metabolism were predicted by antibiotics and Secondary Metabolite analysis shell (antiSMASH) version 5.0 (Blin et al. 2019) and RAST annotation pipeline was carried out using the SEED platform (Aziz et al. 2008). The Venn diagram was constructed by OrthoVenn2 (https://orthovenn2.bioinfotoolkits.net/home), using the generated protein sequences. The draft genome and $16 \mathrm{~S}$ rRNA gene sequences of strain $\mathrm{KVB}^{2} 3^{\top}$ have been deposited at GenBank/EMBL/DDBJ under accession numbers JAESVP000000000 and MN955430respectively. The DNA G+C content of strain $\mathrm{KVB}^{2} 3^{\top}$ was calculated from the genome data.

\section{Chemotaxonomy}

For determining the chemotaxonomic characteristics, the cells were grown in R2A agar at $30^{\circ} \mathrm{C}$ untill the late exponential phase and then harvested by centrifugation. Cellular fatty acids were acquired by saponification, methylation and extraction as reported previously (Kuykendall et al. 1988). The extract was analysed using the Sherlock Microbial Identification system V6.01 (MIS, database TSBA6, MIDI Inc., Newark, DE, USA) and was subsequently compared with the extracts of other type strains.

For the purification of isoprenoid quinones, Sep-Pak Vac cartridges (Waters Associates Inc., Milford MA USA) were used and the extract was analysed by using high-performance lipid chromatography as reported previously (Hiraishi et al. 1996; Collins and Jones 1981).

For carotenoid analysis, the cells were extracted using $10 \mathrm{ml}$ mixture of methanol/acetone $(1: 1, \mathrm{v} / \mathrm{v})$ (Chhetri et al. 2019b). The absorption spectrum of the pigments was assessed with a spectrophotometer (Multiskan GO; Thermo Fisher Scientific).

Polar lipids were extracted as described previously (Minnikin et al. 1984) and analyzed by twodimensional thin-layer chromatography using chloroform/methanol/water $(65: 25: 4 ; \mathrm{v} / \mathrm{v} / \mathrm{v})$ in the first dimension and chloroform/methanol/acetic acid/water (80:15:12:4; $/ \mathrm{v} / \mathrm{v} / \mathrm{v})$ in the second dimension (Minnikin et al. 1984). Appropriate detection reagents (Komagata and Suzuki 1987) were used to identify the spots; molybdophosphoric acid (phosphomolybdic acid reagent, $5 \% \mathrm{v} / \mathrm{v}$ solution in ethanol; SigmaAldrich, Germany) was used to detect total lipids, ninhydrin reagent ( $0.2 \%$ solution; Sigma life Science, 
USA) was used to detect amino lipids, Zinzadze reagent (molybdenum blue spray reagent, $1.3 \%$; Sigma Life Science) was used to detect phospholipids, and a-naphthol reagent was used to detect glycolipids.

\section{Results And Discussion}

\section{Morphology, physiology and biochemical analysis}

Cells of the strain KVB23 ${ }^{\top}$ were facultative anaerobic, Gram-stain-negative, rod-shaped, oxidase-negative, catalase-positive and devoid of flagella. Colonies were white, convex and circular with entire edges. The colour of colonies were white after culture for 5 days and it became slightly brown at the center of the colonies after ten days of incubation at $30^{\circ} \mathrm{C}$ (Fig.1). The strain grew in the presence of $0-2 \%(\mathrm{w} / \mathrm{v}) \mathrm{NaCl}$ (optimum $0 \%$ ), at $7-35^{\circ} \mathrm{C}$ (optimum $30^{\circ} \mathrm{C}$ ) and at $\mathrm{pH} 6.5-7.5$ (optimum $\mathrm{pH} 7.0$ ). It did not show photoautotrophic and photoheterotrophic growth under anaerobic conditions. No absorption maxima were detected at $377,590,803$ and $860 \mathrm{~nm}$ confirmig that the strain $\mathrm{KVB}^{2} 3^{\top}$ did not contain any photosynthetic pigments. In addition, the genome of strain $\mathrm{KVB}^{2} 3^{\top}$ did not have photosynthetic genes. Growth occurred at temperatures ranging from $7-35^{\circ} \mathrm{C}$ (optimum, $30^{\circ} \mathrm{C}$ ), at $\mathrm{pH}$ 6.0-8.0 (optimum, $\mathrm{pH} 7.0$ ) and in the presence of $0-03 \% \mathrm{NaCl}(\mathrm{w} / \mathrm{v}$ : optimum, $0 \%)$. The new isolated was unable to perform anoxygenic photosynthesis or to grow phototrophically under anoxic conditions, and this character can clearly distinguish strain $\mathrm{KVB}^{2} 3^{\top}$ from the species of genus Tabrizicola and Rhodobacter.Growth of strain KVB23 ${ }^{\top}$ was not occured in Jensen's nitrogen free medium. Occurrence of halo zone around the colonies in phosphate-solubilizing agar showed the solubilizing ability of strain KVB23 ${ }^{\top}$ (Fig. S1).In the API ZYM system, the strain $\mathrm{KVB}^{2} 3^{\top}$ displayed positive results for alkaline phosphatase, esterase, esterase lipase, leucine arylamidase, valine arylamidase, trypsin, acid phosphatase, naphthol-AS-BIphosphohydrolase and $\alpha$-glucosidase activities however it displayed negative results for lipase, cystine arylamidase, $\alpha$-chymotrypsin, $\alpha$-galactosidase, $\beta$-galactosidase, $\beta$-glucuronidase, $\beta$-glucosidase, $\mathrm{N}$-acetyl$\beta$-glucosaminidase, $a$-mannosidase and $\alpha$-fucosidase activities. In the API 20NE system, the strain did not reduce nitrate and did not produce indole. Moreover, it did not ferment glucose and did not hydrolyse arginine and gelatin. It only assimilated malic acid but did not assimilate $\mathrm{D}^{-}$-glucose, $\mathrm{L}^{\text {-arabinose, }} \mathrm{D}^{-}$ mannose, $N$-Acetyl-_-glucosamine, D-maltose, potassium gluconate, capric acid, adipic acid, trisodium citrate and phenylacetic acid. KVB23 $3^{\top}$ could be differentiated from other closely related members by using several phenotypic and biochemical properties, such as able to grow in low temperature of $7^{\circ} \mathrm{C}$, could grow in anaerobic condition and able to hydrolyse esculin. Most importantly, strain $\mathrm{KVB}^{2} 3^{\top}$ showed brown pigmentation at the center of the colony after ten days of incubation but the close relatives were not shown the pigmentation. The differentiatingcharacteristics between strain $\mathrm{KVB}^{2} 3^{\top}$ and the members of its related genera within the family Rhodobacteriaceae and also the reference strains were presented in Table 1.

Phylogenetic and genome analysis 
16S rRNA gene sequence of strain $\mathrm{KVB}^{\mathrm{T}}{ }^{\mathrm{T}}$ indicated that strain was most closely related to Tabrizicola fusiformis SY72 ${ }^{\top}$ (96.5\%), Rhodobacter thermarum YIM $73036^{\top}(96.2 \%)$ and Tabrizicola alkalilacus DJC ${ }^{\top}$ (96.0\%). Phylogenetic analysis based on neighbour-joining tree (Fig. 2)further revealed that the novel strain $\mathrm{KVB}^{2} 3^{\top}$, formed a distinct lineage within the family Rhodobacteriaceae, clustering with the clade comprising phototrophic species belonging to the genus Tabrizicola and Rhodobacter, and nonphototrophic species belonging to Falsirhodobacter and Xinfangfangia. Similar results were obtained in both maximum-likelihood (Fig. S2) and maximum parsimony trees (Fig. S3). The topologies of all tree trees were almost same and available in the online version of this article.Phylogenomic tree also gave the similar results (Fig. S4).

The genome size of strain KVB23 ${ }^{\top}$ was found to be $3,808,773 \mathrm{bp}$. The complete genome of strain $\mathrm{KVB} 23^{\top}$ consisted of 3,720 coding genes, 3 rRNA and 46 tRNA genes and 32 pseudogenes. The number of contigs was 21 and $N 50$ value was 446,226 . The $\mathrm{G}+\mathrm{C}$ content of genomic DNA is $63.1 \%$ which is within the range for the members of the family Rhodobacteriaceae. The ANI values between strain $\mathrm{KVB}^{2} 3^{\top}$ and the closely related reference strains $T$. fusiformis KCTC $62105^{\top}, R$. thermarum KCTC $52712^{\top}$ and $F$. deserti KCTC $32408^{\top}$ were $78.2,74.4$ and $72.9 \%$ and the corresponding $\mathrm{dDDH}$ values were $21,19.2$ and $19.4 \%$. These ANI and dDDH values are clearly below the species-delineating thresholds (95\% and $70 \%$, respectively) (Chun et al. 2018; Richter and Rossello-Mora 2009; Stackebrandt and Ebers 2006), supporting the conclusion that strain $\mathrm{KVB}^{\top} 3^{\top}$ represents a novel genus in the family Rhodobacteriaceae. The antiSMASH server revealed eight gene clusters for the biosynthesis of several secondary metabolites; one gene cluster each for redox-cofactor, terpene, Type I polyketide synthase (T1PKS), non-ribosomal peptide synthetase, three gene clusters for hserlactone, and one gene cluster for RRE-element.The presence of three striking hserlactone gene clusters may have potential ecological roles, which may be related to the communication between fungi and bacteria (Shiner et al. 2005). The comparison of biosynthetic gene clusters between strain $\mathrm{KVB}^{2} 3^{\top}$ and its reference strains is provided in Table $\mathrm{S} 1$. According to RAST annotation, 1455 protein encoding genes in whole genome of strain $\mathrm{KVB}^{2}{ }^{\mathrm{T}}$ were classified into 27 functional categories (Table 2). Interesting point was all strains have genes for motility (Flagellar) and chemotaxis except $F$. deserti KCTC $32408^{\top}$. However, all strains were found to be nonflagellated. Strain $\mathrm{KVB}^{2} 3^{\top}$, also had five gene clusters for motility and chemotaxis however it was not flagellated.The genome of strain $\mathrm{KVB} 23^{\top}$ was compared with those of phylogenetically related species belonging to the family Rhodobacteriaceae. Four gene clusters for auxin biosynthesis were also annotated in the genome of strain $\mathrm{KVB}^{2} 3^{\top}$. The main precursor for the synthesis of IAA is typtophan, four genes encoding for tryptophan biosynthesis were also found: tryptophan-rich sensory protein (JAESVP010000001.1), tryptophan 2, 3-dioxygenase (kynA; JAESVP010000002.1), tryptophan synthase subunitbeta (trpB; JAESVP010000003.1) and tryptophan synthase subunit alpha (JAESVP010000005.1).Cobalamin has been suggested to stimulate plant development and could be synthesized either via de novo or salvage pathways. Five gene clusters for cobalamin biosynthesis were also found in the genome of strain KVB23 ${ }^{\top}$. Based on Venn diagrams of protein clusters, Fig S5 showed the number of orthologous clusters shared among strain $\mathrm{KVB}^{2} 3^{\top}$ and other closely related members. 
The major respiratory quinone of the strain $\mathrm{KVB}^{2} 3^{\top}$ was ubiquinone Q-10, which is common in Rhodobacteriaceae family.The polar lipid of strain $\mathrm{KVB}^{\mathrm{T}} 3^{\top}$ were diphosphatidylglycerol (DPG), phoshatidylethanolamine (PE), seven unidentified phosphoglycolipid (PGL), two unidentified aminophosphoglycolipid (APGL), one unidentified glycolipid (GL) and four unidentified lipids ( $L$ ) which characteristically differentiated $\mathrm{KVB}^{2} 3^{\top}$ from other recognized families (Fig. S6). The fatty acid profiles of strain $\mathrm{KVB} 3^{\top}$ and its closely related members were presented in Table 3 . The drastic difference in the major fatty acids also differentiate strain KVB23 ${ }^{\top}$ from other close relatives. Difference in the percentage of major fatty acid $C_{16: 0}, C_{18: 0}$ and summed feature 8 (comprising $C_{18: 1} \omega 7 \mathrm{c}$ and / or $\mathrm{C}_{18: 1} \omega 6 \mathrm{c}$ ) distinguish the strain $\mathrm{KVB}_{2}{ }^{\top}$ from its close relatives. Absence of anteiso $\mathrm{C}_{15: 0}$, iso $\mathrm{C}_{16: 0}$, presence of $\mathrm{C}_{18: 1} \omega 7 \mathrm{c}$ and some other qualitative and quantitative differences in the fatty acid composition between the novel strain $\mathrm{KVB} 3^{\top}$ and other members of the family Rhodobacteriaceaecould considered as a distinguishing characteristics for the novel genus.

Strain $\mathrm{KVB} 23^{\top}$ has the ability to solubilize phosphate and the genome of strain $\mathrm{KVB}^{\top} 3^{\top}$ contains striking genes that may contribute to rice plant growth stimulation and has good application potential in sustainable agriculture.Based on theaforementioned distinct phylogenetic, phenotypic, biochemical, chemotaxonomic and genomic data the novel isolate $\mathrm{KVB} 23^{\top}$ cannot be assigned to any previously recognized bacterial taxa and therefore, we propose that strain $\mathrm{KVB} 3^{\top}$ represents a novel species belonging to a novel genus Fuscibacteroryzaegen. nov., sp. nov., within a novel family, Rhodobacteriaceae fam. Nov.

\section{Description of Fuscibacteroryzaegen. nov.}

Fuscibacter gen. nov. (Fus.ci.bac'ter. L. adj. fuscus, brown; L. n. bacter (from Gr. bakterion) a rod; N.L. masc. n. Fuscibacter, a brown rod).

Cells are Gram-stain-negative, facultative anaerobic, catalase- and oxidase-negative, asporogenous, shortrod shaped, non-flagellated and non-motile. Flexirubin-type pigments are absent. They contained Q-10 as the sole respiratory quinone. The main cellular fatty acids are $C_{16: 0}, C_{18: 0}$ and summed feature 8 (comprising $\mathrm{C}_{18: 1} \omega 7 \mathrm{c}$ and / or $\mathrm{C}_{18: 1} \omega 6$ ). The polar lipids include diphosphatidylglycerol, phoshatidylethanolamine, seven unidentified phosphoglycolipid, two unidentified aminophosphoglycolipid, one unidentified glycolipid and four unidentified lipids. The DNA G+C content of the type strain of the type species is $63.1 \%$. Based on phylogenetic analysis, the genus belongs to the family Rhodobacteriaceae within the phylum Proteobacteria. The type species is Fuscibacteroryzae.

\section{Description of Fuscibacteroryzaesp. nov}

F. oryzaesp. nov. (o.ry'zae. L. fem. n.oryzae, of rice, referring to the isolation of the type strain from the root of a rice plant) 
Cells are Gram-stain negative, aerobic, ovoid to rod-shaped, non-motile, asporogenous, $0.4-0.5 \mu \mathrm{m}$ long and 0.8-1.4 $\mu \mathrm{m}$ wide after 3 days of culture on R2A. Colonies on R2A agar are white to brown pigmented, smooth, circular, convex and have an entire margin. Cells are non-motile, multiply by binary fissionand negative for catalase and oxidase activities. Growth occurs at $7-35^{\circ} \mathrm{C}$ (optimum $25-30{ }^{\circ} \mathrm{C}$ ) and pH $6.0-8.0$ (optimum 6.5-7.0). Hardly tolerates $\mathrm{NaCl}(\mathrm{w} / \mathrm{v}$ ) upto $2 \%$ (optimum $0 \% \mathrm{NaCl}$ ). Good growth occurs on $\mathrm{R} 2 \mathrm{~A}$ agar and NA, weak growth on TSA and no growth on MA and LB. Strain $\mathrm{KVB}^{\top}$ was able to grow in the absence of oxygen and showed negative activities for catalase and oxidase reaction.Strain $\mathrm{KVB}^{2} 3^{\top}$ able to hydrolyze esculin and Tween 20, but not Tween 40 and 60, starch, casein and CM-cellulose. It does not have a vesicular photosynthetic membrane. Moreover, it does not contain bacteriochlorophyll a, carotenoids and flexirubin. Photoautotrophic and photoheterotrophic growth does not occur. Furthermore, photosynthetic pigments are not produced and apparently photosynthetic genes were also not found in the genome of strain KVB23 ${ }^{\top}$. Strain $\mathrm{KVB}_{2} 3^{\top}$ was able to dissolve phosphate when grown in Pikovakaya's medium. The predominant respiratory quinone is ubiquinone $\mathrm{Q}-10$ and the $\mathrm{G}+\mathrm{C}$ content of the genomic DNA of the type strain is $63.1 \%$. The main cellular fatty acids are $C_{16: 0}, C_{18: 0}$ and summed feature 8 (comprising $\mathrm{C}_{18: 1} \omega 7 \mathrm{c}$ and / or $\mathrm{C}_{18: 1} \omega 6$ ). The polar lipids include diphosphatidylglycerol, phoshatidylethanolamine, seven unidentified phosphoglycolipid, two unidentified aminophosphoglycolipid, one unidentified glycolipid and four unidentified lipids.

The type strain KVB23 ${ }^{\top}\left(=\right.$ KACC $21711^{\top}=$ NBRC $\left.114716^{\top}\right)$ was isolated from root of rice plant collectedfromrice field near Ilsan, South Korea. The GenBank accession number of the 16S rRNA gene sequence of the strain $\mathrm{KVB} 23^{\top}$ is MN955430 and its draft genome sequence accession number is JAESVP000000000.

\section{Abbreviations}

KCTC: Korean Collection for Type Cultures

MEGA:Molecular Evolutionary Genetics Analysis

UBCG: up-to-date bacterial core gene

NJ: Neighbour-joining

ML: Maximum-likelihood

MP: Maximum-parsimony

DPG:Diphosphatidylglycerol

PE:Phosphatidylethanolamine

\section{Declarations}




\section{Funding}

This work was supported by a grant from the National Institute of Biological Resources (NIBR), funded by the Ministry of Environment (MOE) of the Republic of Korea (NIBR202002203), and by the National Research Foundation of Korea (NRF) grant funded by the Korea government (MSIT) (2020R1F1A1072647).

\section{Conflicts of interest}

All the authors declare that there is no conflict of interest.

\section{Authors' contributions}

GC isolated the bacterium, designed the study, performed the phenotypic and biochemical characterization, and wrote the original draft; MK, JK, IK, YS helped with the analysis of taxonomic data; TS designed and supervised the study, and edited the original draft.

\section{Ethics approval}

This study does not describe any experimental work related to human.

\section{References}

1. Garrity GM, Bell JA, Lilburn T. Familyl. Rhodobacteraceae fam.nov (2005) In Brenner DJ, Krieg NR, Staley JT, Garrity GM. (editors) Bergey's Manual of Systematic Bacteriology New York: Springer; pp 161

2. Hetharua B, Min D, Liao H, Lin Li'an, Xu H et al (2018) Litorivita pollutaquae gen. nov., sp. nov., a marine bacterium in the family Rhodobacteraceae isolated from surface seawater of Xiamen Port, China. Int J Syst EvolMicrobiol 68:3908-3913

3. Das S, Lyla PS, Khan SA (2007) Biogeochemical processes in the continental slope of Bay of Bengal: I. bacterial solubilization of inorganic phosphate Rev. Biol. Trop 55:1-9

4. Chhetri G, Kim J, Kim I, Kim H et al (2020a) Adhaeribacter rhizoryzae sp. nov., a fibrillar matrix producing bacterium isolated from the rhizosphere of rice plant. Int J Syst Evol Microbiol 70:53825388

5. Chhetri G, Yang D, Choi J et al (2018) Edaphorhabdus rosea gen. nov., sp. nov., a new member of the family Cytophagaceae isolated from soil in South Korea. Antonie van Leeuwenhoek 111:2385

6. Bernardet JF, Nakagawa Y, Holmes B (2002) Proposed minimal standards for describing new taxa of the family Flavobacteriaceae and emended description of the family. Int J Syst Evol Microbiol 52:1049-1070

7. Fautz E \& Reichenbach H (1980) A simple test for flexirubin-type pigments. FEMS Microbiol Lett 8:87-91 
8. Kim J, Chhetri G, Kim I, Kim H, Kim MK, Seo T (2019) Methylobacterium terrae sp. nov., a radiationresistant bacterium isolated from gamma ray-irradiated soil. J Microbiol 57:959-966

9. Kim I, Kim J, Chhetri G et al (2019) Flavobacterium humi sp. nov., a flexirubin-type pigment producing bacterium, isolated from soil. J Microbiol. 57:1079-1085

10. Smibert RM, Krieg NR (1994) Phenotypic characterization. In: Gerhardt P (ed) Methods for general and molecular bacteriology. American Society for Microbiology, Washington DC, pp 607-654

11. Chhetri G, Kim J, Kim I, Seo T (2019a) Lysobacter caseinilyticus, sp. nov., a casein hydrolyzing bacterium isolated from sea water. Antonie van Leeuwenhoek 112:1349-1356

12. Kim OS, Cho YJ, Lee K, Yoon SH, Kim M, Na H, Park SC, Jeon YS, Lee JH. \& other authors (2012) Introducing EzTaxon-e: a prokaryotic 16S rRNA gene sequence database with phylotypes that represent uncultured species. Int J Syst Evol Microbial 62:716-721

13. Kumar S, Stecher G and Tamura K (2016) Mega 7: Molecular evolutionary genetics analysis in version 7.0 for bigger datasets. Mol Biol Evol 33:1870-1874

14. Thompson JD, Gibson TJ, Plewniak F, Jeanmougin F, Higgins DG (1997) The CLUSTAL_X windows interface: flexible strategies for multiple sequence alignment aided by quality analysis tools. Nucleic Acids Res 25:4876-4882

15. Felsenstein J (1985) Confidence limits on phylogenies: An approach using the bootstrap. Evolution, 39:783-791 Rzhetsky A, Nei M (1992) A simple method for estimating and testing minimumevolution trees. Mol Biol Evol 9:945-967

16. MeierKolthoff JP, Auch AF, Klenk HP, Göker M (2013) Genome sequence-based species delimitation with confidence intervals and improved distance functions. BMC Bioinf 14:60

17. Na SI, Kim YO, Yoon SH et al (2018) UBCG: up-to-date bacterial core gene set and pipeline for phylogenomic tree reconstruction. J Microbiol 56:281-285

18. Blin K, Shaw S, Steinke K et al (2019) antiSMASH 5.0: updates to the secondary metabolite genome mining pipeline. Nucleic Acids Res 47:W81-W87

19. Aziz RK, Bartels D, Best AA et al (2008) The RAST server: rapid annotations using subsystems technology. BMC Genomics 9:75

20. Kuykendall LD, Roy MA, O'Neill JJ, Devine TE (1988) Fatty acids, antibiotic resistance and deoxyribonucleic acid homology groups of Bradyrhizobium japonicum. Int J Syst Evol Microbiol 38:358-361

21. Hiraishi A, Ueda Y, Ishihara J, Mori T (1996) Comparative lipoquinone analysis of influent sewage and activated sludge by highperformance liquid chromatography and photodiode array detection $\mathrm{J}$ Gen Appl Microbiol 42: 457-469

22. Collins MD, Jones D. Distribution of isoprenoid quinone structural types in bacteria and their taxonomic implications. Microbiol Rev 1981;45:316-354

23. Chhetri, G., Kim, J., Kim, H. et al (2019b) Pontibacter oryzae sp. nov., a carotenoid-producing species isolated from a rice paddy field. Antonie van Leeuwenhoek 112:1705-1713 
24. Minnikin DE, O'Donnell AG, Goodfellow M, Alderson G, Athalye M, Schaal A, Parlett JH (1984). An integrated procedure for the extraction of bacterial isoprenoid quinones and polar lipids. J Microbiol Methods 2:233-241

25. Komagata K, Suzuki KI (1987) Lipid and cell-wall analysis in bacterial systematics. Methods Microbiol 19:161 205

26. Chun J, Oren A, Ventosa A, Christensen H, Arahal DR, da Costa MS, Rooney AP, Yi H, Xu XW, De Meyer S, Trujillo ME (2018) Proposed minimal standards for the use of genome data for the taxonomy of prokaryotes. Int J Syst Evol Microbiol 68:461-466

27. Richter M, Rosselló-Móra R (2009) Shifting the genomic gold standard for the prokaryotic species definition. Proc Natl Acad Sci 106:19126-19131

28. Stackebrandt E, Ebers J (2006) Taxonomic parameters revisited: tarnished gold standards. Microbiol Today 33:152-155

29. Shiner EK, Rumbaugh KP and Williams SC (2005) Interkingdom signaling: Deciphering the language of acylhomoserine lactones. FEMS Microbiol Rev. 29:935-947

\section{Tables}

Table 1. Physiological and biochemical characteristics of strain $\mathrm{KVB}^{2} 3^{\top}$ and closely related type strains of the family Rhodobacteriaceae. All data were examined in this study unless otherwise indicated. 


\begin{tabular}{|c|c|c|c|c|}
\hline Characteristics & 1 & 2 & 4 & 3 \\
\hline Isolation source & Plant root & $\begin{array}{l}\text { Industrial } \\
\text { wastewater }\end{array}$ & Sediment & Sandy soil \\
\hline Cell shape & $\begin{array}{l}\text { Ovoid to } \\
\text { rod }\end{array}$ & fusiform & Ovoid to rod & rod \\
\hline Colony color & $\begin{array}{l}\text { white to } \\
\text { brown }\end{array}$ & Translucent white & Brown & $\begin{array}{l}\text { Lemon } \\
\text { yellow }\end{array}$ \\
\hline Catalase/oxidation & $-/-$ & $+/+$ & $+/+$ & $+/+$ \\
\hline Anaerobic growth & + & - & - & + \\
\hline Optimal growth & $25-30$ & $30-37$ & $37-45$ & 30 \\
\hline $\begin{array}{l}\text { Temperature range for } \\
\text { growth }\end{array}$ & $7-35$ & $15-40$ & $20-55$ & $10-40$ \\
\hline Growth in $3 \% \mathrm{NaCl}$ & - & - & + & + \\
\hline $\mathrm{NaCl}$ range for growth & $0-2$ & $0-1.5$ & $0-3.5$ & $0-10$ \\
\hline Media for optimum growth & $\mathrm{R} 2 \mathrm{~A}$ & $\mathrm{R} 2 \mathrm{~A}$ & $\mathrm{R} 2 \mathrm{~A}$ & TSA \\
\hline Optimal pH & $6.5-7.0$ & $6.0-7.0$ & $7.0-7.5$ & 7 \\
\hline Phototrophic growth & - & - & + & - \\
\hline Photosynthetic pigments & - & - & $\begin{array}{l}\text { Bacteriochlorophyl } \\
\text { II } a\end{array}$ & - \\
\hline Internal membrane system & - & - & + & - \\
\hline$\beta$-Caroten production & - & - & + & \\
\hline pufL and pufM genes & - & - & + & - \\
\hline \multicolumn{5}{|l|}{$\begin{array}{l}\text { Enzyme activities (API } \\
\text { ZYM) }\end{array}$} \\
\hline Lipase & - & + & + & + \\
\hline Cystine arylamidase & - & - & + & + \\
\hline Trypsin & + & - & - & + \\
\hline Acid phosphatase & + & + & - & - \\
\hline $\begin{array}{l}\text { Naphtol-AS-BI- } \\
\text { phosphohydrolase }\end{array}$ & + & - & - & + \\
\hline$\beta$-galactosidase & - & - & + & + \\
\hline$\beta$-galactosidase & + & + & + & + \\
\hline$\beta$-glucosidase & - & + & - & + \\
\hline
\end{tabular}




\begin{tabular}{|lcccc|}
\hline N-acetyl- $\beta$-glucosaminidase & - & + & - & - \\
\hline API 20NE & - & + & & + \\
\hline Arginine dihydrolase & - & + & - & + \\
\hline Urease & + & + & - & - \\
Esculin hydrolysis & - & - & - & - \\
\hline D-glucose & - & + & + & + \\
\hline L-arabinose & - & + & + & + \\
\hline D-mannose & - & + & + & - \\
\hline D-mannitol & - & + & + & - \\
\hline N-Acetyl-D-glucosamine & - & + & + & + \\
\hline D-maltose & + & - & - & $67.3^{\mathrm{c}}$ \\
\hline malic acid & 63.5 & $63.7+0.2^{\mathrm{a}}$ & $66^{\mathrm{b}}$ & - \\
\hline DNA G+C content (mol\%) & & & & + \\
\hline
\end{tabular}

Strains: 1, KVB23 ${ }^{\top} ; 2$, Tabrizicola fusiformis KCTC $62105^{\top}$; 3, Rhodobacter thermarum KCTC $52712^{\top}$; 4 , Falsirhodobacter deserti KCTC $32408^{\top}$.

*Data taken from: a (Ko et al. 2018); b (Khan et al 2018) and c (Wang et al 2015); +, Positive; -, negative.

Table 2. Comparison of numbers of genes associated with functional categories in genomes of strain KVB23 ${ }^{\top}$ and phylogenetically related species in the family Rhodobacteriaceae. 


\begin{tabular}{|c|c|c|c|c|}
\hline Strains & 1 & 2 & 3 & 4 \\
\hline Cofactors, Vitamins, Prosthetic Groups, Pigments & 136 & 137 & 119 & 38 \\
\hline Cell Wall and Capsule & 23 & 31 & 36 & 5 \\
\hline Virulence, Disease and Defense & 34 & 63 & 35 & 5 \\
\hline Potassium metabolism & 4 & 8 & 4 & - \\
\hline Photosynthesis & - & - & 2 & - \\
\hline Miscellaneous & 15 & 28 & 19 & 6 \\
\hline Phages, Prophages, Transposable elements, Plasmids & 20 & 33 & 28 & 1 \\
\hline Membrane Transport & 37 & 77 & 35 & 19 \\
\hline Iron acquisition and metabolism & 4 & 9 & 4 & 0 \\
\hline RNA Metabolism & 36 & 46 & 35 & 10 \\
\hline Nucleosides and Nucleotides & 98 & 91 & 91 & 33 \\
\hline Protein Metabolism & 170 & 191 & 181 & 58 \\
\hline Cell Division and Cell Cycle & - & - & - & - \\
\hline Motility and Chemotaxis & 5 & 16 & 15 & 0 \\
\hline Regulation and Cell signaling & 25 & 19 & 17 & 6 \\
\hline Secondary Metabolism & 4 & 5 & 5 & 0 \\
\hline DNA Metabolism & 71 & 66 & 69 & 28 \\
\hline Fatty Acids, Lipids, and Isoprenoids & 52 & 75 & 62 & 3 \\
\hline Nitrogen Metabolism & 43 & 42 & 22 & 7 \\
\hline Dormancy and Sporulation & 1 & 1 & 1 & 0 \\
\hline Respiration & 106 & 110 & 93 & 13 \\
\hline Stress Response & 65 & 66 & 55 & 10 \\
\hline Metabolism of Aromatic Compounds & 9 & 50 & 39 & 2 \\
\hline Amino Acids and Derivatives & 243 & 259 & 228 & 82 \\
\hline Sulfur Metabolism & 3 & 18 & 3 & 3 \\
\hline Phosphorus Metabolism & 24 & 21 & 23 & 12 \\
\hline Carbohydrates & 227 & 252 & 188 & 34 \\
\hline
\end{tabular}


Strains: 1 , KVB23 ${ }^{\top} ; 2$, Tabrizicola fusiformis KCTC $62105^{\top}$; 3 , Rhodobacter thermarum KCTC $52712^{\top}$; 4 , Falsirhodobacter deserti KCTC $32408^{\top}$.

Table 3. Cellular fatty acid compositions (\%) of strain $\mathrm{KVB}^{2} 3^{\top}$ and reference strains of the closely related species.

\begin{tabular}{|lllll|}
\hline Fatty acids & $\mathbf{1}$ & $\mathbf{2}$ & $\mathbf{3}$ & $\mathbf{4}$ \\
\hline $\mathrm{C}_{14: 0}$ & 1 & $\mathrm{TR}$ & - & 1.2 \\
\hline $\mathrm{C}_{16: 0}$ & 13.1 & 6.8 & 25.1 & 6.8 \\
\hline $\mathrm{C}_{17: 0}$ & 1.5 & 1.6 & $\mathrm{TR}$ & $\mathrm{TR}$ \\
\hline $\mathrm{C}_{18: 0}$ & 16.9 & 3.5 & 22 & 10.6 \\
\hline iso $\mathrm{C}_{16: 0}$ & - & 1.5 & - & - \\
\hline iso $\mathrm{C}_{11: 0} 30 \mathrm{H}$ & 1.7 & $\mathrm{TR}$ & - & - \\
\hline $\mathrm{C}_{10: 0} 30 \mathrm{H}$ & 5.5 & 3.5 & 6.9 & 3.8 \\
\hline anteiso $\mathrm{C}_{15: 0}$ & - & 1.2 & 1.3 & - \\
\hline $\mathrm{C}_{18: 1} \omega 7 \mathrm{c}$ & 4.8 & - & 38.9 & 60.8 \\
\hline $\mathrm{C}_{16: 0} \mathrm{~N}$ alcohol & $\mathrm{TR}$ & - & 2.5 & 1.8 \\
\hline $\mathrm{C}_{18: 1} \omega 7 \mathrm{c} 11$-methyl & 7.4 & 1.8 & 1.2 & 15 \\
\hline Summed features* & & & & \\
\hline 3 & $\mathrm{TR}$ & - & 1 & $\mathrm{TR}$ \\
\hline 7 & - & 1.2 & $\mathrm{TR}$ & $\mathrm{TR}$ \\
\hline 8 & 48 & 78.3 & - & - \\
\hline
\end{tabular}

Strains: 1, KVB23 ${ }^{\top}$; 2, Tabrizicola fusiformis KCTC $62105^{\top}$; 3 , Rhodobacter thermarum KCTC $52712^{\top}$; 4 , Falsirhodobacter deserti KCTC $32408^{\top}$. Prior to fatty acid extraction, all strains were grown on R2A agar at $30^{\circ} \mathrm{C}$ for 3 days except $R$. thermarum KCTC $52712^{\top}$, it is grown at $40^{\circ} \mathrm{C}$ on R2A. Values are percentages of total fatty acids, and only fatty acids representing more than $1 \%$ for at least one of the strains are shown. -, Not detected; TR, trace amounts $(<1 \%)$.

* Summed features represent groups of two or three fatty acids that cannot be separated using MIDI system. Summed feature 3 (composed of $\mathrm{C}_{16: 1} \omega 7 \mathrm{c}$ and/or $\mathrm{C}_{16: 1} \omega 7 \mathrm{c}$ and/or iso- $\mathrm{C}_{15: 0} 2-\mathrm{OH}$ ), summed 
feature 7 (composed of $\mathrm{C}_{19: 1} \omega 7 \mathrm{c}$ and / or $\mathrm{C}_{19: 1} \omega 6 \mathrm{c}$ ) and summed feature 8 comprises $\mathrm{C}_{18: 1} \omega 7 \mathrm{c}$ and/or $\mathrm{C}_{18: 1} \omega 6 \mathrm{c}$.

\section{Figures}
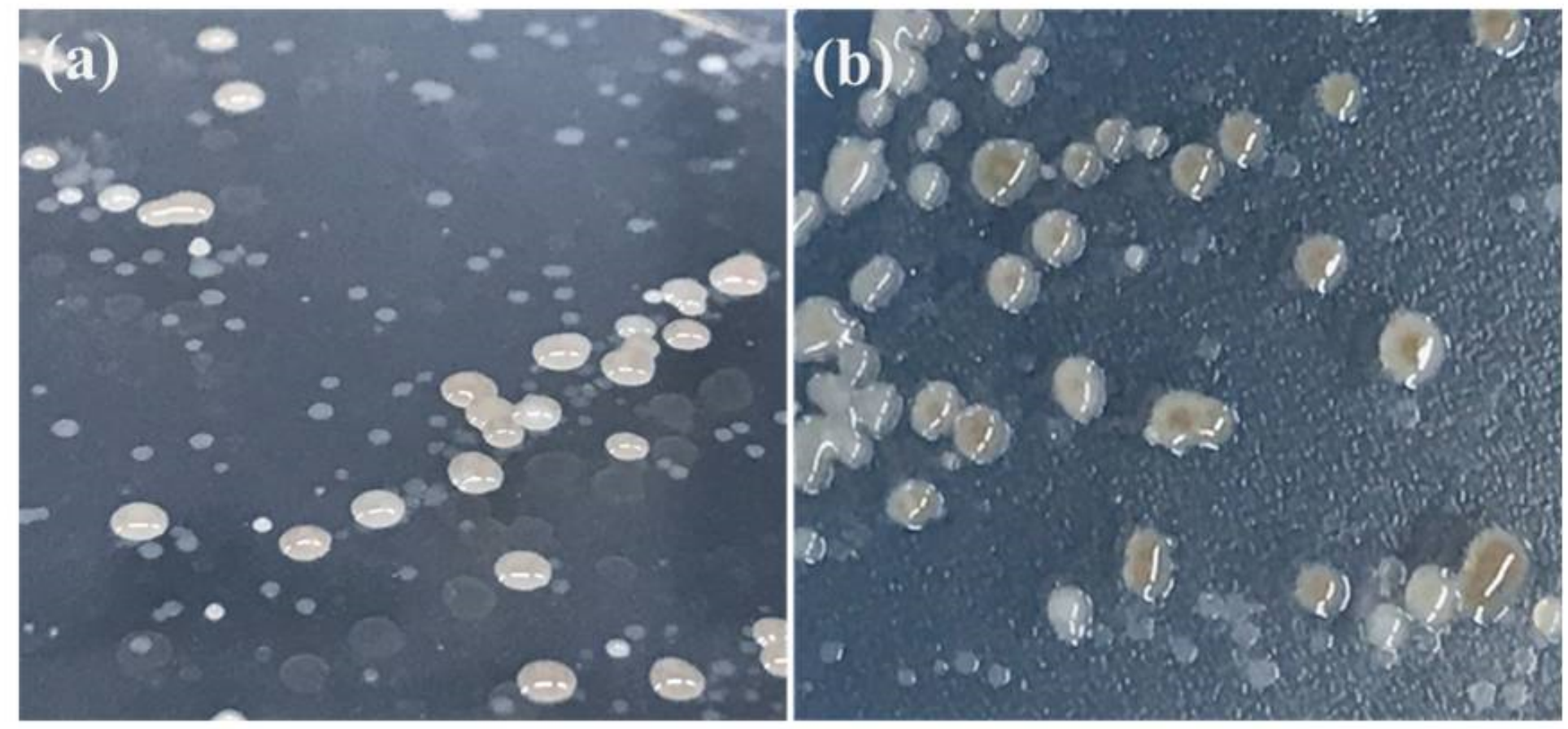

(c)

\section{(d)}

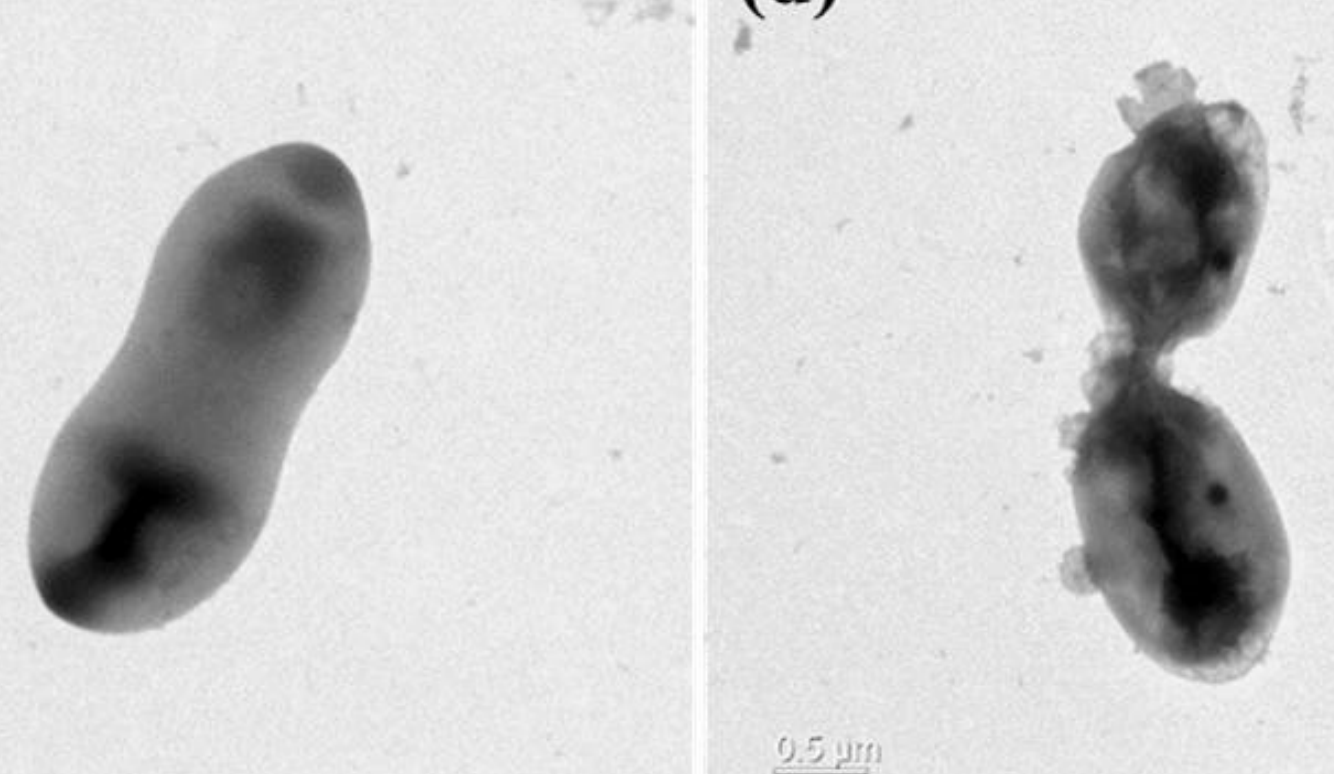

$92 \mu \mathrm{m}$

\section{Figure 1}

Creamy white colonies (a) turns to brown at the center (b) after 10 days of incubation at $30^{\circ} \mathrm{C}$. Transmission electron microscopy of strain KVB23T, four days old.Cells were grown for four days and 
seven days and negatively stained with phosphotungstic acid after growth for one week at $30^{\circ} \mathrm{C}$ on $\mathrm{R} 2 \mathrm{~A}$ agar. Bar (c) and (d) $0.2 \mu \mathrm{m}$ and $0.5 \mu \mathrm{m}$. Figure (d) showing budding cells.

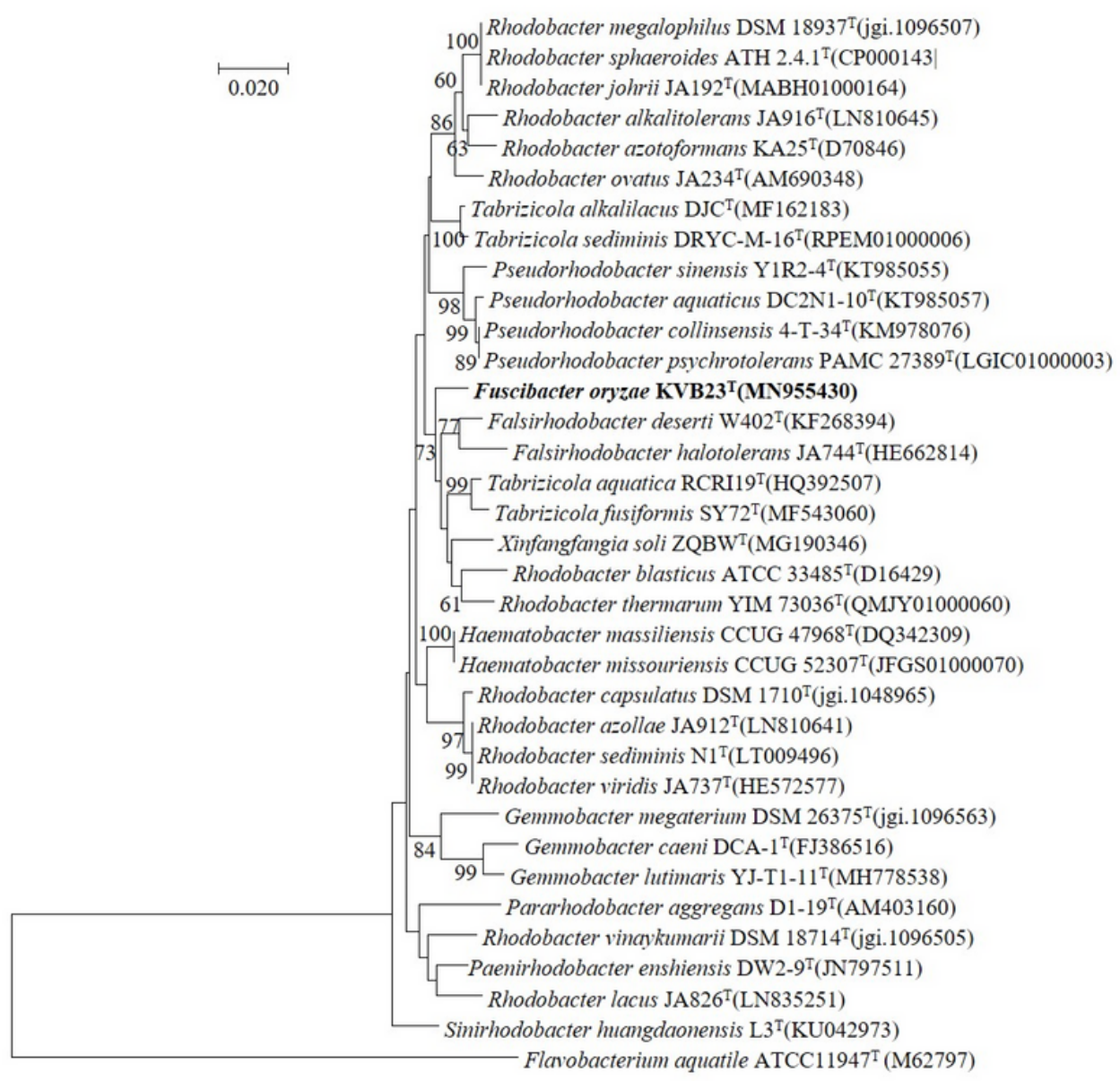

Figure 2

Neighbour-joining tree based on 16S rRNA gene sequences showing the relationship between strain KVB23Tand related species. Bootstrap values (based on 1000 replications) greater than $50 \%$ are shown at branch points. Flavobacterium aquatile ATCC11947T (M62797) was used as an out-group. Bar, 0.020 substitutions per nucleotide position.

\section{Supplementary Files}

This is a list of supplementary files associated with this preprint. Click to download.

- Fuscibacteroryzaesupplementary.docx 